\title{
Fully automated analysis of grain chemistry, size and morphology by CCSEM: examples from cement production and diamond exploration
}

\author{
Nynke Keulen, Dirk Frei, Stefan Bernstein, Mark T. Hutchison, Christian Knudsen and Lucas Jensen
}

Computer-controlled scanning electron microscopy (CCSEM) combines the advantages of energy dispersive X-ray spectrometry (EDX) with those of digital image analysis of back-scattered electron (BSE) micrographs. CCSEM analysis of a wide range of geological or non-geological materials has been introduced at the Geological Survey of Denmark and Greenland (GEUS) as a fast and reliable method to determine both the chemistry of individual grains and bulk samples. The chemical analysis is combined with measurements of the two-dimensional size and morphology of every single grain.

The CCSEM technique was developed in the early 1980s for characterisation of coal minerals (Huggins et al. 1980; Lee \& Kelly 1980) and studies of synthetic crystals for super-conductors and catalysts (Lin \& Barnes 1984). Soon it found a broader application in the study of dust particles and fibres in lung tissue of mine workers (Friedrichs 1987), in the analyses of aerosols for air quality control and source emission characterisation (e.g. Heasman \& Watt 1989) and the degree of sintering and consolidation of coal ash deposits (e.g. Huffman $e t$ al. 1994). CCSEM has been used in the earth sciences for the determination of the sediment budget of a lake (Yin \& Johnson 1984), for the characterisation of soil and dust (Pirrie et al. 2004), for provenance analysis of ilmenite-bearing beach sands (Knudsen et al. 2005; Bernstein et al. 2008), and provenance studies on sandstones in oil-bearing basins (Frei et al. 2005). Other areas where CCSEM has been applied range widely and include characterisation of small inclusions, e.g. impurities in metal alloys or steel (Schwoeble et al. 1988), analyses of gun-shot residues (e.g. Steffen et al. 2007), and analyses of bladder stones obtained from a skeleton found in a Mesolithic cave-tomb (D'Alessio et al. 2005). In this paper, we demonstrate the benefits of the method with examples from the cement industry and from diamond prospecting.

Fig. 1. A: CCSEM sample of beach sediment from Jylland, Denmark, divided into a number of frames in a grid. Part of the grid is outlined in white. Grains of different chemical compositions (different grey values) are embedded in epoxy resin. B: Enlargement of one of the frames of the grid (indicated in red in $\mathbf{A}$ ). The guard region (yellow) prevents double or incomplete measurements of grains (see text). The grey-level threshold function selects the grains one by one from the matrix for analyses of chemical composition, size and shape. Analysed grains are shown in red; the image represents a snapshot of the CCSEM procedure.

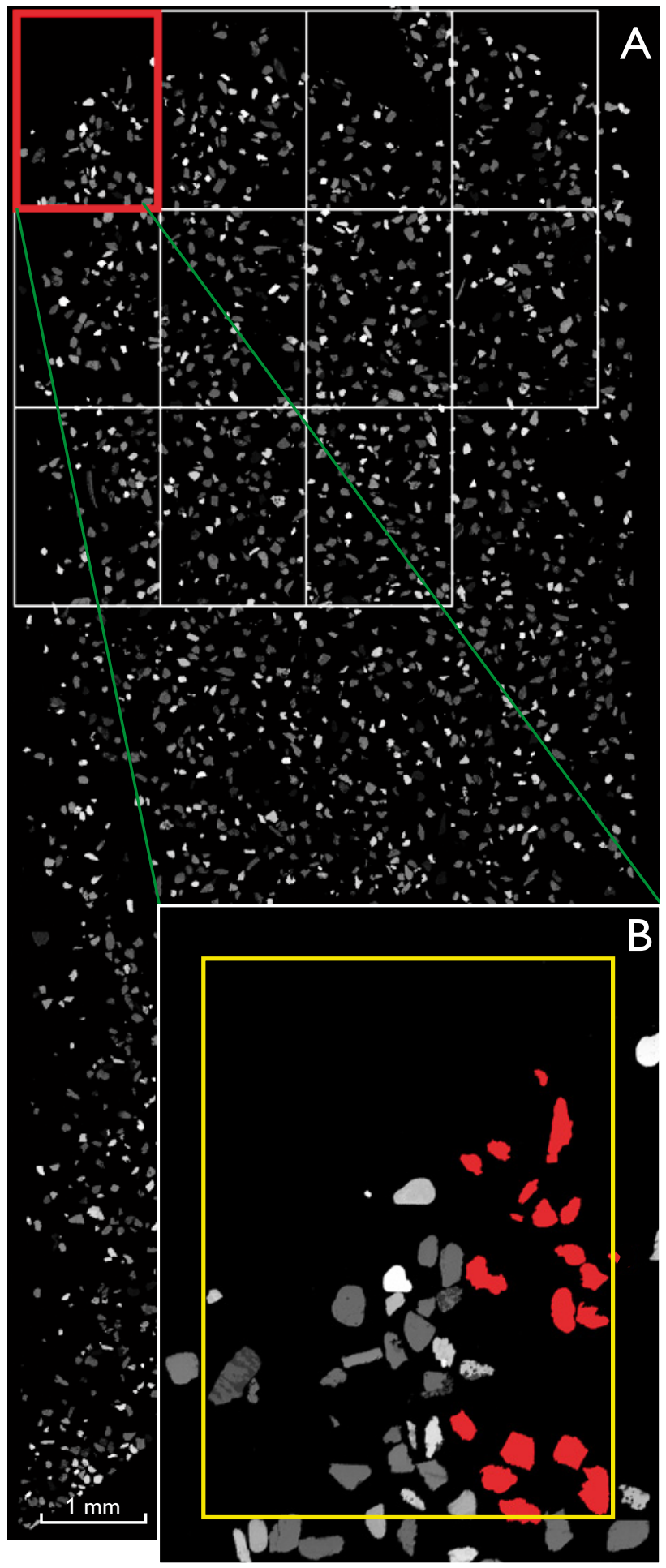




\section{Analytical technique}

\section{Sample preparation}

Sample material may, for example, consist of (1) a representative part of a bulk sample, (2) carefully selected grains mounted on double-sided tape, or (3) a heavy mineral separation of a bulk sample. Grains, beads, and powders of both geological and non-geological origin can be analysed. For most studies, approximately $1 \mathrm{~g}$ of sample material was mounted in epoxy resin, using a technique that ensures that almost every grain is completely embedded in the epoxy, without touching any neighbouring grains (Frei et al. 2005). The epoxy mounts are cut to show a representative part of the mount, subsequently polished and coated with carbon to enhance their conductivity. However, it is also possible to use thin sections of sample material prepared in a similar way.

\section{CCSEM analysis}

The CCSEM analysis was undertaken using a Philips XL40 SEM equipped with two EDX detectors: a Thermo Nanotrace $30 \mathrm{~mm}^{2}$ window and a Pioneer Voyager $2.710 \mathrm{~mm}^{2}$ window $\mathrm{Si}(\mathrm{Li})$ detector. The tungsten filament of the SEM was operated with an acceleration voltage of $17 \mathrm{kV}$, a filament current of typically $50-70 \mu \mathrm{A}$, and the sample was placed at a distance of $10 \mathrm{~mm}$ from the detector. The Noran System SIX software package was used to automatically collect X-ray spectra, grain size and morphology of all particles and to recalculate the data following the Proza $(\varphi \rho Z)$ data correction and the filtering quantification technique. The technique described here is an improvement of the method described by Frei et al. (2005) and Bernstein et al. (2008).

The samples were studied in the BSE contrast mode of the electron microscope where the individual particles appear as different shades of grey in their black epoxy matrix (Fig. 1). Grey-level intensity thresholding by the image analysis function integrated in the software created a binary image of the BSE micrograph and allowed for the separation and selection of individual grains (Fig. 1B). A grid of image frames covering the whole sample area was defined by feeding the end-coordinates of the sample to the computer and by setting the required magnification (typically 30-100x) for the analysis (Fig. 1A). Grids consisted of 15 to 60 frames with approximately 20-35 grains per frame. A guard region between each frame ensured that double measurements of large particles in the sample was avoided and that only grains that lay completely within the image frame were included for analysis and thus recorded the true shape of grains. A 'hole-fill' function enabled more precise measurement of the grain size and shape from the binary image. Because the grains were mounted in epoxy resin in such a way that they do not touch each other, no grain separation techniques had to be used, as commonly applied in automatic particle analysis software. Thus, the original 2-D grain shape and grain size were completely available for analysis, without the introduction of artefacts by grain erosion and dilation or median filtering. All standard grain-shape factors can be measured. The smallest grains in the sample can be excluded from the analysis to avoid the measurement of particles that are only a few pixels in size, especially if a good grain morphology resolution is required.

The created binary image formed the basis for the measurements of the grain chemistry. The software forced the microscope to scan within the perimeter of each grain to obtain the chemistry of either the whole grain area or from a single point in the centre of the grain mass. A typical spectrum for one particle contained 1000-2000 counts for the highest peak. Spectra with a very low number of counts can be removed to ensure good measurement statistics. Commonly, 800-1200 grains were measured in approximately two hours.

The Noran software produces a results table that lists shape, size and chemistry for each individual grain. All spectrum files and image frames, with a typical size of $1024 \times 774$ pixels, are stored after analysis. Spectrum files can be reprocessed to include accidentally omitted elements retrospectively, without the need to physically reanalyse the sample. The chemical data are further reduced using a software package that is connected to a mineral library database for automatic phase recognition and data storage.

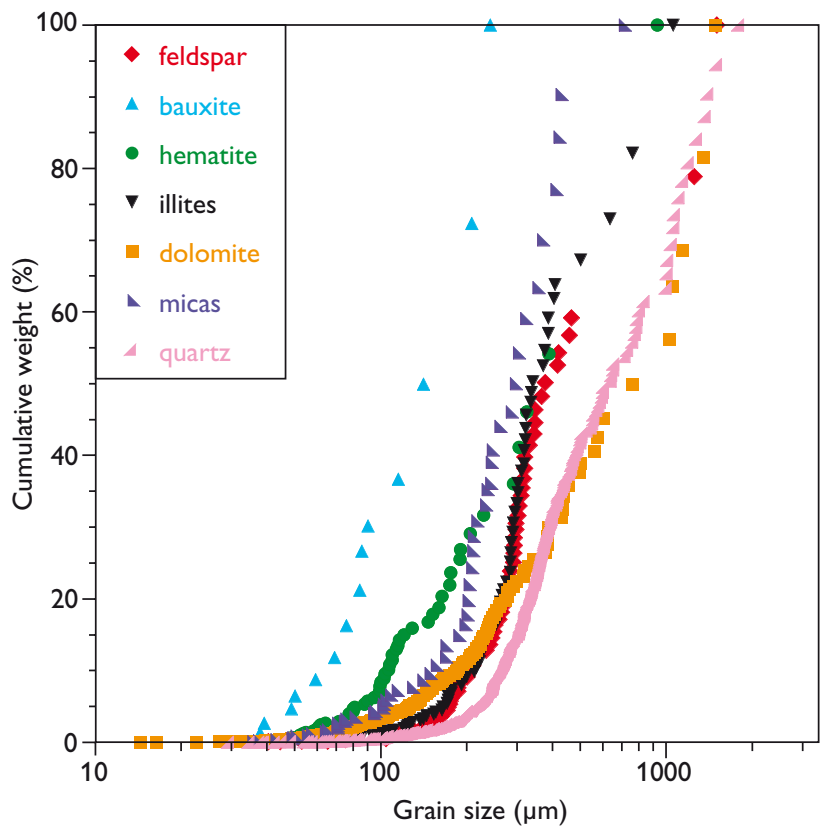

Fig. 2. Grain-size distribution diagram for seven minerals from raw materials used in the cement industry. Grain mineralogy and grain size were determined with CCSEM 


\section{Application of CCSEM as a practical solution}

\section{Quality control of raw materials in cement production}

For cement production, raw materials are crushed to fine grain sizes before they are mixed and reacted at high temperatures in a kiln. To optimise the performance of the grinding mill and the sintering process an investigation of the grain-size distribution of the limestone, iron ore, clay and sand fractions of the cement was undertaken. The grain-size distribution of the individual components in particular is of great importance for further processing of the raw material into cement clinker.

The raw material was sieved into different grain-size fractions and treated with hydrochloric acid to decrease the amount of calcium carbonate in the raw material. The size fraction of 10-2000 $\mu \mathrm{m}$ was analysed with CCSEM to determine the grain-size distribution and grain chemistry. Figure 2 shows the grain-size distribution for seven different minerals. The mica, illite, and feldspar grains show uniform grain-size distributions, whereas bauxite, hematite and particularly dolomite grains show ranges of size distributions over two orders of magnitude. The hematite grains display a bimodal-size distribution. These findings demonstrate that CCSEM is a suitable option for routine quality control and improvement of the production process.

\section{CCSEM: a fast and reliable tool for diamond prospecting?}

Determinations of the elemental composition of macro-crystalline phases in kimberlitic rocks or in detrital sediment samples are an important tool in diamond exploration. The major and minor element compositions of certain minerals are diagnostic for igneous rocks of mantle origin, and in some cases also represent a defined probability that the crystallisation of these phases occurred under conditions where diamond is stable. The ratios between $\mathrm{Cr}$ and $\mathrm{Ca}$ concentrations of $\mathrm{Mg}$-rich garnets and the $\mathrm{Cr}$ and $\mathrm{Ca}$ concentrations of eclogitic garnets are examples where such probability fields have been defined (Fig. 3; Grütter et al. 2004). A standard method for analysing the composition of garnets and other macrocrystalline phases is to measure the concentration of approximately ten to fifteen oxides with an electron microprobe (EMP). EMP is a dependable, yet time-consuming and relatively expensive method. We therefore tested the potential of CCSEM analysis as a faster and cheaper method to measure the composition of macrocrystals in kimberlitic rocks.

We used indicator minerals from the 'Garnet Lake' kimberlite body in West Greenland, where diamonds are common (Hutchison 2005). A series of hand-picked pyrope (garnet)

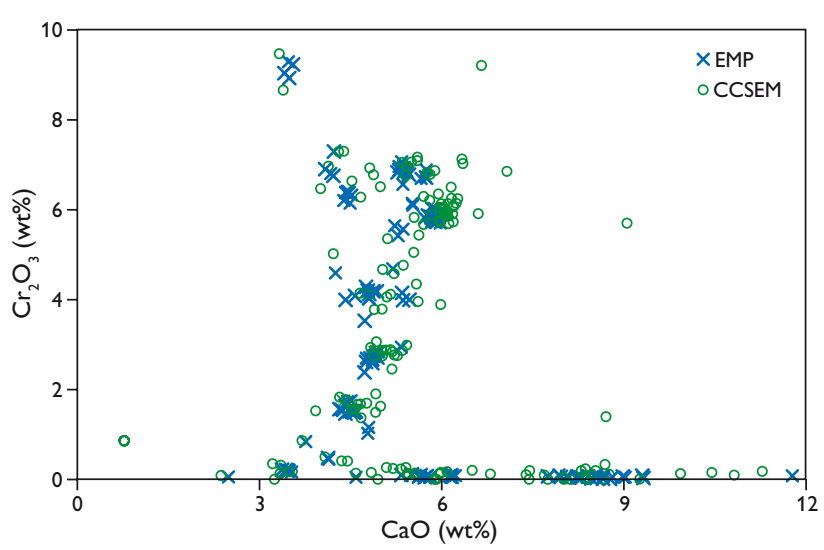

Fig. 3. Comparison of electron microprobe (EMP) and CCSEM measurements for chromium oxide and calcium oxide in Mg-rich garnets from diamondbearing rocks. Note the good correlation between the results obtained with CCSEM and the EMP data.

grains were mounted in epoxy resin. The sample was analysed using CCSEM, with extended counting times to ensure good statistics: the relative error in the reproducibility of the measurements is $c .1-2 \%$ for major elements and $c .4-8 \%$ for minor elements. The accuracy of CCSEM was tested by comparing the results with compositional data obtained from electron microprobe analyses for the same minerals (as reported by Hutchison 2005). Even with extended counting time, a sample consisting of 200 grains can be analysed in 1-3 hours, with less than half an hour of operator time. An excellent reproduction of the EMP measurements was achieved by CCSEM (Fig. 3); the statistical correlation between the two methods for these elements is $70 \%$. The few outliers reflect those garnet grains that show a compositional gradient from core to rim. The EMP point analyses were carried out on the cores of the grains, whereas the CCSEM analyses average the whole surface of the grains, therefore providing slightly different results that are closer to the bulk composition of the grains. The vast majority of the garnet grains analysed by CCSEM plot in the same classification field as do the grains according to the EMP measurements. CCSEM is therefore a good option for reliable and more rapid measurements of garnet minerals in diamond-bearing rocks.

\section{Validity of the CCSEM measurements}

Comparison between EMP and CCSEM shows high accuracy of the CCSEM for minor elements. Figure 4 shows the precision of the CCSEM method for a major element (93.71 $\mathrm{wt} \%)$, a minor element (2.19 wt\%) and a trace element $(0.21$ $\mathrm{wt} \%)$, measured on the same sample. Five sets of measurements at nine different maximum peak count settings (equivalent to nine different time periods) were undertaken to evaluate the reproducibility of the data. For standard single spot or single grain analyses the relative errors are high com- 


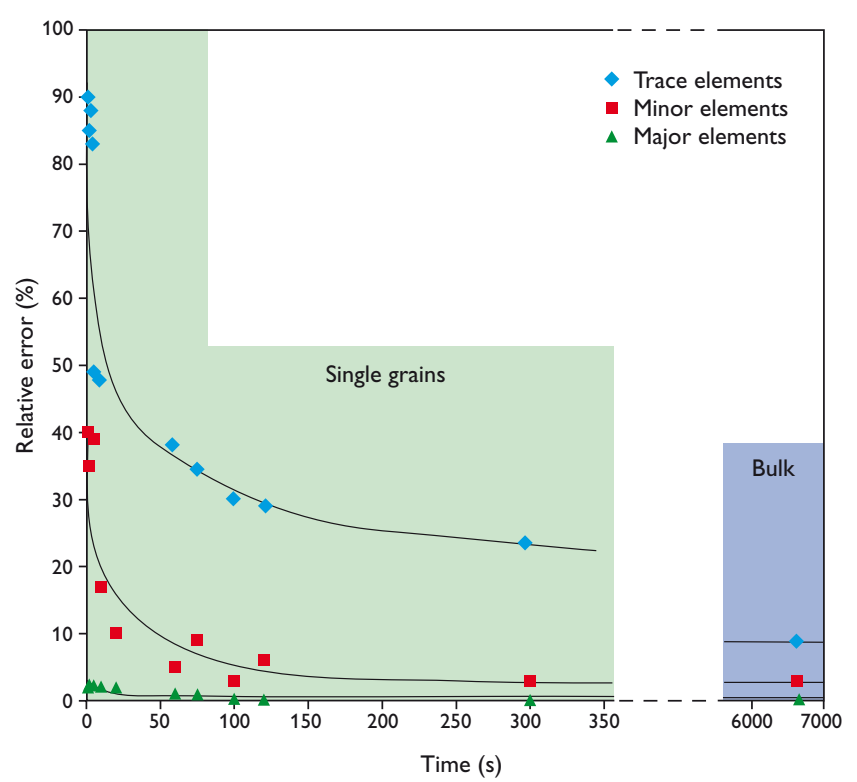

Fig. 4. Precision of single grain and bulk sample CCSEM analyses as a function of measurement times. Two detectors were used for the analyses. The precision increases with counting time.

pared to other analytical methods: $2-3 \%$ for major elements (>20 wt \%), 5-10\% for minor elements (>2 wt\%) and $50-100 \%$ for elements present in smaller quantities. However, these figures can easily be improved by slightly increasing the counting time (Fig. 4). The precision of bulk sample CCSEM measurements is very high: as an effect of the long counting times the relative errors are reduced to $<0.2 \%$ for major elements, $<2 \%$ for minor elements and $<15 \%$ for trace elements. This shows that the analysis time can be usefully tailored to the sample set depending on the required precision of the measurements and the time available. Applied to diamond prospecting, measurement times could be adjusted depending on how marginal the sample is in the diamond stability field.

The examples discussed above indicate that CCSEM provides an accurate and precise way to rapidly measure single grain and bulk compositions of minerals and of other geological and non-geological materials. Coupled with measurements of the grain size and other grain parameters for the individual particles, this technique is a potent tool to solve a wide range of problems.

\section{Acknowledgement}

Hudson Resources Inc. is thanked for provision of garnet samples.

\section{References}

Bernstein, S., Frei, D., McLimans, R.K., Knudsen, C. \& Vasudev, V.N. 2008: Application of CCSEM to heavy mineral deposits: source of high-Ti ilmenite sand deposits of South Kerala beaches, SW India. Journal of Geochemical Exploration 96, 25-42.

D’Alessio, A., Bramanti, E., Piperno, M. Naccarato, G. Vergamini, P. \& Fornaciari, G. 2005: An 8500-year-old bladder stone from Uzzo cave (Trapani): fourier transform-infrared spectroscopy. Archaeomotry 47, 127-136.

Frei, D., Rasmussen, T., Knudsen, C., Larsen, M., Whitham, A. \& Morton, A. 2005: Linking the Faroese area and Greenland: new methods and techniques used in an innovative, integrated provenance study. Fróðskaparrit 43, 96-108.

Friedrichs, K.H. 1987: Electron microscopic analyses of dust from the lungs and the lymph nodes of talc-mine employees. American Industry Hygiene Association Journal 48, 626-633.

Grütter, H.S., Gurney, J.J., Menzies, A.H. \& Winter, F. 2004: An updated classification scheme for mantle-derived garnet, for use by diamond explorers. Lithos 77, 841-857.

Heasman I. \& Watt, J. 1989: Particulate pollution case studies which illustrate uses of individual particle analysis by scanning electron microscopy. Environmental Geochemistry and Health 11, 157-162.

Huffman, G.P. et al. 1994: Investigation of ash by microscopic and spectroscopic techniques. In: Williamson, J. \& Wigley, F. (eds): The impact of ash deposition on coal fired plants. Proceedings of the Engineering Foundation Conference (20-25 June 1993, Solihull, Birmingham, UK), 409-423. London: Taylor \& Francis.

Huggins, F.E., Kosmack, D.A., Huffman, G.P. \& Lee, R.J. 1980: Coal mineralogy by SEM analysis. Scanning Electron Microscopy 1, 531-540.

Hutchison, M.T. 2005: Diamondiferous kimberlites from the Garnet Lake area, West Greenland: exploration, methodologies and petrochemistry. In: Secher, K. \& Nielsen, M.N. (eds): Workshop on Greenland's diamond potential. 7-9 November 2005 in Copenhagen. Extended abstracts. Danmarks og Grønlands Geologiske Undersøgelse Rapport 2005/68, 33-42.

Knudsen, C., Frei, D., Rasmussen, T., Rasmussen, E. S. \& McLimans, R. 2005: New methods in provenance studies based on heavy minerals: an example from Miocene sands in Jylland, Denmark. Geological Survey of Denmark and Greenland Bulletin 7, 29-32.

Lee, R.J. \& Kelly, J.F. 1980: Overview of SEM-based automated image analysis. Scanning Electron Microscopy 1, 303 only.

Lin, M.C. \& Barnes, R.G. 1984: Mössbauer spectroscopy and scanning electron microscopy study of iron-graphimet. Journal of Applied Physics 55, 2294 2296.

Pirrie, D., Butcher, A.R., Power, M.R., Gottlieb, P. \& Miller, G.L. 2004: Rapid quantitative mineral and phase analysis using automated scanning electron microscopy (QemSCAN); potential applications in forensic geoscience. In: Pye, K. \& Croft, D.J. (eds): Forensic geoscience: principles, techniques and applications. Geological Society Special Publication (London) 232, 123-136.

Schwoeble, A.J., Dalley, A.M., Henderson, B.C. \& Casuccio, G.S. 1988: Computercontrolled SEM and microimaging of fine particles. Journal of Metals 40, 11-14. Steffen, S., Otto, M., Niewoehner, L., Barth, M., Brozek-Mucha, Z., Biegstraaten, J. \& Horvath, R. 2007: Chemometric classification of gunshot residues based on energy dispersive X-ray microanalysis and inductively coupled plasma analysis with mass-spectrometric detection. Spectrochimica Acta B62, 1028 1036.

Yin, C. \& Johnson, D.L. 1984: An individual particle analysis and budget study of Onondaga Lake sediments. Limnology \& Oceanography 29, 1193-1201.

\section{Authors' addresses}

N.K., D.F., M.T.H. \& C.K., Geological Survey of Denmark and Greenland, Øster Voldgade 10, DK-1350 Copenhagen K, Denmark. E-mail: ntk@geus.dk S.B., Avannaa Resources Ltd., Geological Museum, University of Copenhagen, Øster Voldgade 5-7, DK-1350 Copenhagen K, Denmark.

L.J., FLSmidth A/S, Vigerslev Allé 77, DK-2500 Valby, Denmark. 